\title{
Globe
}

Revue internationale d'études québécoises

\section{Chantal Bouchard : La Langue et le nombril. Histoire d'une obsession québécoise, Montréal, Fides, 1998, 303 p.}

\section{Karine Cellard}

Volume 2, numéro 2, 1999

URI : https://id.erudit.org/iderudit/1000479ar

DOI : https://doi.org/10.7202/1000479ar

Aller au sommaire du numéro

Éditeur(s)

Globe, Revue internationale d'études québécoises

ISSN

1481-5869 (imprimé)

1923-8231 (numérique)

Découvrir la revue

Citer ce compte rendu

Cellard, K. (1999). Compte rendu de [Chantal Bouchard : La Langue et le nombril. Histoire d'une obsession québécoise, Montréal, Fides, 1998, 303 p.] Globe, 2(2), 175-176. https://doi.org/10.7202/1000479ar d'utilisation que vous pouvez consulter en ligne.

https://apropos.erudit.org/fr/usagers/politique-dutilisation/ 


\section{RECENSIONS}

novatrices dans l'étude des réalités politiques». Or, l'intention de Pestieau tient manifestement plus du tour d'horizon.

Augustin Simard Université Laval

\section{Chantal Bouchard \\ La Langue et le nombril. \\ Histoire d'une obsession québécoise \\ Montréal, Fides, 1998, 303p.}

Dans son récent ouvrage, Chantal Bouchard entreprend l'étude du discours tenu sur la langue au Québec de la colonisation aux années 70 . À travers l'analyse d'essais, de conférences, de chroniques journalistiques ou de courriers de lecteurs ayant la langue pour objet, l'auteure retrace l'état du français à différentes époques, en s'attardant principalement à l'image qu'ont eue d'elle ses locuteurs. La Langue et le nombril nous propose une histoire de l'identité collective des Québécois telle que révélée par le discours métalinguistique. "Le discours sur la langue reflète et traduit les moindres fluctuations de la structure identitaire, fluctuations qui sont des réponses aux transformations des conditions d'existence de cette collectivité et des rapports de celle-ci avec les autres sociétés» (p. 285).

Dans un souci constant de lier langue et société, l'analyse des documents métalinguistiques est toujours précédée d'importantes mises en contexte. Plusieurs perspectives historiques sont adoptées à cet effet, telles que l'histoire sociale, l'histoire politique ou économique. La psychologie est aussi invoquée par la sociolinguiste pour faire le lien entre psychés individuelle et collective. Dans cette perspective, une nation, au même titre qu'un individu, peut vivre une crise identitaire si elle se voit exposée à des changements brusques (pression d'un Autre plus puissant, pression de changements socioéconomiques, etc.) auxquels elle est mal préparée. Le discours sur la langue nous révèle les comportements adoptés à chaque époque par la collectivité québécoise face aux changements et aux pressions 


\section{REVUE INTERNATIONALE D'ÉTUDES QUÉBÉCOISES}

sociales qu'elle a subis. D'objet d'étude, le discours métalinguistique devient instrument heuristique de notre inconscient collectif.

L'ouvrage s'ouvre sur une mise au point définitionnelle des principales notions utilisées (culture, identité, identité collective). L'auteure retrace ensuite d'une façon générale l'évolution du français québécois et les raisons socio-historiques expliquant son écart avec la norme parisienne. La suite de l'étude, en deux parties traitant respectivement des périodes avant et après la Confédération, se consacre aux discours sur la langue et à leurs contextes. La période suivant l'Acte constitutionnel fait l'objet d'une étude plus poussée, puisqu'elle marque le début d'une conscience négative de la langue qui affectera profondément le Québec jusqu’à la Révolution tranquille. L'auteure y identifie quatre étapes (1867-1910, 1910-1940, 1940-1960, 1960-1970), chacune présentant une conscience linguistique particulière où sont stigmatisés certains éléments de la langue (anglicismes, régionalismes, etc.), et où sont préconisés des moyens différents pour en améliorer la qualité. L'analyse se clôt sur les mesures législatives entreprises par le gouvernement provincial dans les années 60 . Ces mesures ont favorisé l'émergence d'une nouvelle sécurité linguistique tout en témoignant de la volonté des Québécois de se responsabiliser face à la langue.

La Langue et le nombril explicite le rapport délicat unissant les Québécois à leur variété de français, qu'ils ont dû à la fois défendre comme différence culturelle et accuser pour en améliorer la qualité. Si l'état de notre langue est encore aujourd'hui sujet de préoccupation constante, le livre de Chantal Bouchard met en perspective les torts qu'on lui attribue, en démontrant ce que le concept de norme linguistique comporte d'historique et de culturel. Ouvrage général de grande qualité, il exploite de manière fort intéressante et originale la question abondamment traitée de l'identité québécoise.

Karine Cellard Centre d'études québécoises Université de Montréal 